\title{
Post-transplantation lymphoproliferative disorder in a child with multivisceral transplant
}

\author{
Gabriella L. Crane • Edward Y. Lee
}

Received: 9 February 2010 /Revised: 13 March 2010/Accepted: 20 April 2010/Published online: 8 May 2010

(C) Springer-Verlag 2010

A 7-year-old girl presented with multiple complaints, including fever, nausea and fatigue, 5 months after a multivisceral transplant for pseudo-obstruction. A chest radiograph showed pulmonary nodules (curved arrows) and a diffuse nodular appearance of the stomach (straight arrows) (Fig. 1). A CT revealed innumerable enhancing pulmonary nodules, mediastinal adenopathy, diffuse nodularity of the gastric wall (curved arrows) and bilateral renal masses (straight arrows) (Fig. 2). A biopsy of polypoid gastric

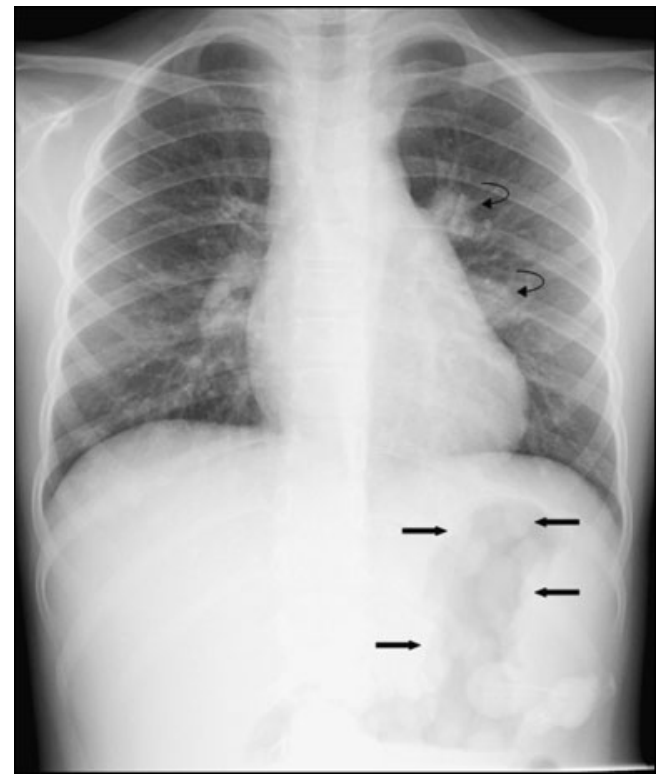

Fig. 1 Frontal chest radiograph

\footnotetext{
G. L. Crane $\cdot$ E. Y. Lee $(\bowtie)$

Department of Radiology,

Children's Hospital Boston and Harvard Medical School,

300 Longwood Ave.,

Boston, MA 02115, USA

e-mail: Edward.Lee@childrens.harvard.edu
}

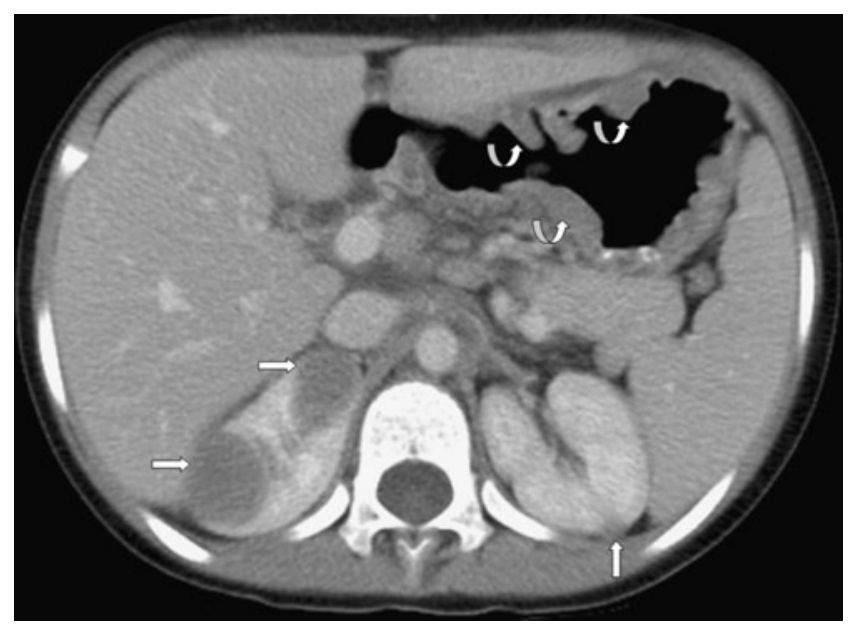

Fig. 2 Axial CT image

lesions revealed Epstein-Barr virus (EBV)-associated posttransplantation lymphoproliferative disorder (PTLD).

PTLD refers to a group of diseases ranging from lymphoid hyperplasia to neoplasia and can be intranodal or extranodal. Most cases are associated with B-lymphocyte proliferation and EBV infection [1]. PTLD usually occurs within 1 year of transplantation and is most prevalent in multivisceral transplant recipients [2]. Although intra-abdominal organs are most frequently affected, particularly the liver and GI tract, sites of involvement vary with the type of allograft [2]. Imaging features depend on the organs involved, and tissue sampling is required for diagnosis and classification.

\section{References}

1. Borhani A, Hosseinzadeh K, Almusa O et al (2009) Imaging of posttransplantation lymphoproliferative disorder after solid organ transplantation. Radiographics 29:981-1002

2. Cockfield SM (2001) Identifying the patient at risk for posttransplant lymphoproliferative disorder. Transpl Infect Dis 3:70-78 